\title{
Capital Social e Dilemas da Ação Coletiva: Avaliando os Resultados de um Centro Comunitário de Produção voltado para Agricultores Familiares Assentados no Mato Grosso do Sul
}

\author{
André Augusto Pereira Brandão ${ }^{1}$ \\ Nilton Cesar SANTOS ${ }^{2}$
}

\begin{abstract}
Resumo
Este artigo discute os problemas relacionados à ação coletiva e à cooperação entre agricultores familiares, produtores de leite, assentados pelo Instituto Nacional de Colonização e Reforma Agrária, que atuam junto a um Centro Comunitário de Produção (CCP). O locus empírico da investigação foi o Assentamento Itamarati II, situado no município de Ponta Porã-MS. Através de pesquisa que utilizou instrumentos de coleta de dados qualitativos e quantitativos, identificamos que, apesar do incremento de renda obtido com o beneficiamento e a comercialização coletiva do produto principal destas famílias, características comunitárias locais relacionadas à baixos níveis de capital social determinam impedimentos ao aprofundamento da cooperação entre elas. Esta configuração acaba por gerar uma situação na qual os agricultores familiares não desenvolvem cadeias de confiança intersubjetiva e passam a atuar como fornecedores individuais de leite para o próprio empreendimento que construíram coletivamente. Nas conclusões buscamos explicar analiticamente quais as variáveis sociais que explicam a conformação desta situação.
\end{abstract}

Palavras-chave: Agricultura familiar. Centro comunitário de produção. Dilemas da ação coletiva. Capital social.

1 Professor-Doutor Associado do Programa de Estudos Pós-graduados em Politica Social da UFF. E-mail: aapbuff@globo.com.

2 Doutorando em Política Social pela UFF e estatístico do “Depto.de Responsabilidade Social e Projetos com a Sociedade” da Eletrobrás. E-mail: nilton.santos@eletrobras.com. 


\title{
Social Capital and Dilemmas of Collective Action: \\ Evaluating the Results of a Community Production Center \\ facing Family Farmers set up in a Settlement in Mato Grosso Do Sul
}

\begin{abstract}
This paper discusses the problems related to collective action and cooperation between family farmers, milk producers is based on data from a Community Production Center - CCP set up in a settlement of the Brazilian National Institute for Colonization and Agrarian Reform - Incra. The empirical locus of the investigation was the Settlement Itamarati II, in the municipality of Ponta Pora-MS. Through research instruments used to collect qualitative and quantitative data, we found that, despite the income increase obtained with the processing and collective marketing of the main product of these families, local community characteristics related to low levels of social capital, determine impediments to closer cooperation among families. This configuration ends up generating a situation where the farmers do not develop inter-subjective trust chains and begin to act as individual milk suppliers to the undertaking which built collectively. The conclusions seek to explain analytically which social variables that explain this conformation.
\end{abstract}

Keywords: Family farming. Community production center. Dilemmas of collective action. Social capital.

\section{INTRODUÇÃO}

Este artigo deriva de uma pesquisa que realizou uma avaliação dos resultados de um projeto de geração de renda, financiado pelas Centrais Elétricas Brasileiras S.A. (Eletrobras), junto a agricultores familiares assentados. Tal projeto denomina-se Centro Comunitário de Produção (CCP) e surgiu em 2003, atrelado ao Programa Luz para Todos, lançado em novembro daquele ano, no governo do presidente Luiz Inácio Lula da Silva.

Defato, oProgramaLuz para Todos consistiuemuma ampliação do antigo Programa Luz no Campo. No âmbito deste segundo, já havia sido identificado que a utilização da energia nessas novas áreas 
se traduzia em um consumo somente doméstico. Os objetivos do Programa Luz para Todos implicavam em atingir áreas rurais que careciam de atendimento de energia elétrica e, consequentemente, promover a melhoria das condições de vida de espaços mais isolados no país. Assim, o projeto dos Centros Comunitários de Produção foi desenvolvido como elemento auxiliar, visando criar oportunidades de geração de renda e atribuir uma finalidade produtiva para esse novo insumo disponível para as comunidades.

Os Centros Comunitários de Produção são unidades compostas por um conjunto de máquinas e equipamentos para produção, processamento, conservação e/ou armazenagem de produtos agropecuários produzidos no âmbito da agricultura familiar $^{3}$. Estas instalações podem ser pequenas estruturas, galpões ou qualquer tipo de edificação que atenda às exigências legais, sanitárias, ambientais e demais requisitos técnicos. Esses projetos espalhados pelo país estão sediados em comunidades rurais marcadas pela pobreza e pela vulnerabilidade. As atividades desenvolvidas pelos Centros Comunitários de Produção são variadas: resfriamento de leite, fabricação de farinha de mandioca, processamento de tomate, produção de doces e compotas de frutas, fabricação de rapadura e açúcar mascavo a partir da cana de açúcar, produção de suco de uvas e processamento de hortaliças e legumes. Em 2014, a Eletrobras contava com 23 CCPs instalados nas cinco regiões do país, atendendo em torno de 1.230 famílias de agricultores.

Neste projeto, a Eletrobrás, além do aporte financeiro para a compra dos equipamentos utilizados no empreendimento, também se encarrega da gestão do processo de implantação, da articulação junto

3 Forma de organização produtiva em que os critérios adotados para orientar as decisões relativas à exploração agrícola não se subordinam unicamente pelo ângulo da produção / rentabilidade econômica, mas leva em consideração também as necessidades e objetivos da família. Contrariando o modelo patronal, no qual há completa separação entre gestão e trabalho, no modelo familiar estes fatores estão intimamente relacionados (CARMO, 2000). 
aos parceiros, além de realizar o monitoramento do projeto. Como demais parceiros, se apresentam o poder público municipal, que geralmente contribui com a doação do material para a edificação da unidade e o engenheiro para acompanhar a obra; o órgão de extensão rural, que pode ser de nível municipal ou estadual (que fica responsável por prestar assistência técnica); a concessionária de distribuição de energia elétrica4, que se responsabiliza pela instalação elétrica da unidade e dos equipamentos; e a associação comunitária que reúne os agricultores familiares que serão beneficiados. Esta última fornece a mão de obra para a construção da unidade.

Neste artigo nos deteremos especificamente nos Centros Comunitários de Produção instalados no ano de 2011 no Assentamento Itamarati II, que dista $16,5 \mathrm{Km}$ da sede do município de Ponta Porã. Este assentamento foi criado em 2004 pelo Instituto Nacional de Colonização e Reforma Agrária (INCRA) e agrega um contingente de aproximadamente 2.000 famílias de pequenos agricultores que estavam dispersos por dois acampamentos do Movimento dos Trabalhadores Sem Terra, situados próximos deste município. As propriedades possuem em média 6 hectares. A atividade econômica principal é a criação de gado leiteiro, seguido da agricultura. Algumas famílias produzem agricultura de subsistência (em geral milho, feijão e arroz) com mão-de-obra doméstica. Mais recentemente ocorreu a adesão de parte dos assentados à produção de soja. No referido assentamento estão implantados oito Centros Comunitários de Produção voltados para a atividade leiteira (através da instalação de tanques de resfriamento de leite). A administração destes é de responsabilidade da Associação dos Agricultores Familiares do Assentamento Itamarati II, que firmou convênio com a Eletrobras para a instalação do projeto.

4 Refere-se às empresas que fazem a comercialização de energia entre a unidade consumidora e a unidade transmissora. Exemplo: Light, Ampla, Cemig. 
Devido às limitações de tempo e orçamento que pairaram sobre a pesquisa que originou este artigo, produzimos um estudo de caso do Centro Comunitário de Produção Boa Esperança. A escolha do mesmo se deveu ao fato de ser aquele em cujo desenho há maior previsão de incorporação de famílias beneficiárias (170) o que poderia assegurar maior robustez nos resultados encontrados.

Realizamos a pesquisa junto à totalidade dos agricultores familiares vinculados ao CCP Boa Esperança, entre final de 2013 e início de 2014. A investigação articulou metodologias quantitativas e qualitativas. Assim, além de aplicarmos um questionário fechado que foi respondido pelos responsáveis pelos domicílios, também realizamos um grupo focal com estes e entrevistamos as lideranças comunitárias locais, bem como os responsáveis pelos órgãos de assistência técnica rural em atuação naquele espaço. Nossa perspectiva é que os resultados passíveis de serem obtidos no estudo deste Centro Comunitário de Produção possibilitem níveis razoáveis de generalização para os demais sete implantados em Ponta Porã, uma vez que todos operam no âmbito do mesmo assentamento e congregam um grupo populacional homogêneo.

Assim como os demais CCPs implantados no Assentamento Itamarati II, o CCP Boa Esperança compreende a instalação de um tanque para resfriamento de leite. Até a instalação deste, a produção leiteira do assentamento era em grande parte (cerca de 80\%) comercializada através de uma empresa de laticínios localizada no município de Dourados-MS (a 150 Quilômetros de distância), que mantinha um resfriador no assentamento e monopolizava a compra do leite produzido. Os demais $20 \%$ era utilizado para a fabricação de queijo e requeijão que chegava ao mercado local. Segundo o projeto inicial, a implantação dos Centros Comunitários de Produção possibilitaria a negociação da produção leiteira em uma gama muito mais ampla de mercados, o que redundaria na obtenção de melhores 
preços de venda. Ou seja, na medida em que os agricultores familiares locais passassem a dispor de resfriadores coletivos próprios, poderiam decidir de forma democrática possibilidades mais vantajosas de escoamento da produção e consequentemente de obtenção de renda elementos que potencialmente redundariam em estímulo ao aumento da produção por parte das famílias beneficiadas.

Schmitz e Santos (2013) apontam que a produção leiteira, especialmentenas pequenas unidades de produção familiar, representa fonte de renda, forma de trabalho familiar, maior liquidez, condições para se manter no campo, garantia de entradas financeiras mensais além do produto e seus derivados servirem para o consumo da própria família melhorando as condições de vida destes agricultores. Segundo Wanderley (2004), a agricultura familiar carrega uma tradição baseada não somente na centralidade familiar, mas também nas formas de produzir e na sua maneira de viver. Na medida em que se encontra inserida em um contexto social globalizado, necessita se adaptar às novas formas de produção e de vida em sociedade. Assim, mesmo integrada de alguma forma ao mercado e atendendo às suas exigências, a modernização dessa agricultura não vai reproduzir o modelo clássico da empresa capitalista, e sim o modelo familiar. Isto porque a lógica familiar que configura suas práticas, que advêm de uma tradição camponesa, não é rompida, inspirando e orientando a atuação desse agricultor nos novos contextos em que está inserido. A família contínua a ser o objetivo principal, conduzindo as estratégias de produção e de reprodução, além de ser a instância imediata de decisão (WANDERLEY, 2004).

Guanziroli e Cardim (2000) revelam que mesmo diante da escassez de crédito, a agricultura familiar consegue ser mais eficiente do que a agricultura patronal. Produzindo mais com menos, o agricultor familiar consegue intensificar o uso da terra, aproveitando ao máximo a área total de que dispõe. Apesar desse potencial da 
agricultura familiar, é notória a carência de estruturas que viabilizem a produção frente aos desafios impostos pelo mercado - que condiciona um modelo que privilegia a maximização do lucro e da produção, desconsiderando os aspectos sociais das famílias e muitas vezes forçando-as ao abandono de suas terras (SANTOS et al., 2014).

Exatamente neste contexto, emerge a proposta de um projeto de apoio ao desenvolvimento da agricultura familiar por meio da introdução de novos formatos de beneficiamento de seus insumos. No entanto, para que esses pequenos agricultores possam ter ganhos mais robustos, é necessário que o princípio da cooperação seja norteador de um processo que vise fomentar uma produção em escala capaz de gerar poder de negociação. Este é o ponto central deste artigo. Em que medida projetos locais de geração de renda para a agricultura familiar possibilitam o incremento da capacidade organizativa local e garantem níveis adequados de adesão por parte dos membros destas comunidades rurais?

\section{Pensando a cooperação e os dilemas da ação Coletiva}

Para iniciar esta discussão é fundamental trazer uma definição do chamado "dilema da ação coletiva", tal como proposto em Olson (1999). A característica básica deste é que:

[...]mesmo que todos os indivíduos de um grupo sejam racionais e centrados em seus próprios interesses, e que saiam ganhando se, como grupo, agirem para atingir seus objetivos comuns, ainda assim eles não agirão voluntariamente para promover esses interesses comuns e grupais. (OLSON, 1999, p. 14).

Segundo Olson (1999), a ação coletiva somente será efetivada se existirem elementos de coerção ou incentivos individuais, para além do ganho possível com o alcance do objetivo comum. Isto porque, mesmo que os custos de cooperar sejam menores que os benefícios 
que poderiam ser alcançados coletivamente, será mais racional não cooperar se tal cooperação não gerar diferença no bem produzido ou na possibilidade de consumo do mesmo.

Tipicamente estes seriam os casos em que estão implicados "benefícios coletivos", definidos por Olson (1999, p. 26) como aqueles que se forem consumidos por um determinado membro do grupo, não poderão ser negados a outros membros deste mesmo grupo5. Assim, o interesse comum dos membros do grupo em obter um benefício coletivo não será necessariamente suficiente para que cada um individualmente contribua para esta obtenção. Um membro racional do grupo pode desertar de participar e esperar que os demais membros produzam o bem que não lhe poderá ser negado. Este indivíduo seria o free-rider ${ }^{6}$, um agente racional e movido pelo auto interesse, que espera que os demais cooperem para a produção do bem que ele poderá então consumir, sem ter despendido nenhum custo.

Na proposição teórica apresentada por Olson (1999), grupos onde a contribuição de cada indivíduo para a produção do bem coletivo não pode ser notada (posto ser reduzida) e implica em custos7 tendem a gerar comportamentos de deserção. Tais grupos são definidos então como "latentes". Exatamente nestes, o "dilema da ação coletiva" seria mais disseminado. No entanto, se todos os membros atuarem com a mesma perspectiva de maximizar seus ganhos, esperando consumir o benefício sem investir em sua produção, obviamente este não será produzido. Está ai o dilema: do ponto de vista da racionalidade coletiva uma cooperação irrestrita seria positiva para todos, mas do ponto de vista da racionalidade individual desertar é estrategicamente mais promissor.

5 Esta definição é devedora da noção de "bem público", cunhada em 1954 por Samuelson (1954).

6 Este conceito, em tradução livre, se refere ao "carona", ou seja, ao indivíduo que apesar de usufruir de um dado benefício coletivo, não está disposto a colaborar com a sua produção.

7 Olson (1999) não está se referindo somente a custos econômicos, mas também de variadas origens, ou seja, custos morais, políticos, etc. 
Olson (1999) avança apontando a hipótese de que a ação coletiva seria mais facilmente produzida em grupos pequenos. Isto por que nestes uma estratégia de deserção e não cooperação seria identificada facilmente por todos os membros e, portanto, o desertor receberia sanções imediatas. Por sua vez, a existência do free-rider diminuiria o custo global de produção do bem.

No entanto, como mostraremos com detalhes mais adiante neste artigo, nossa pesquisa empírica detectou enorme dificuldade associativa e cooperativa entre membros de um grupo substancialmente pequeno de agricultores familiares. Frente a isto, nossa hipótese é que devemos considerar o que Putnam (2007) denomina como "capital social" como outro elemento fundamental para avaliar os "dilemas da ação coletiva". Ou seja, ainda que os grupos pequenos tenham menor probabilidade de "latência", a ausência de capital social pode gerar nestes impedimentos à cooperação capazes de ensejar problemas semelhantes aos encontrados nos grandes grupos.

O arcabouço teórico construído por Putnam (2007), que usaremos aqui, deriva de uma pesquisa empírica de longa duração (cerca de 20 anos), que lançou mão de metodologias quantitativas e qualitativas, com o objetivo geral de contribuir para a "compreensão do desempenho das instituições democráticas" (PUTNAM, 2007, p. 19). Nesta pesquisa, que teve como escopo a Itália a partir dos anos 1970, Putnam verificou a existência de padrões regionais diferentes de desempenho institucional. Explicar a gênese e reprodução histórica destes padrões constituiu o horizonte de sua investigação.

Partindo do conhecimento acumulado na ciência política, Putnam (2007) também indica que a não cooperação visando à promoção de benefícios coletivos não é, necessariamente, irracional. Seja pelos elementos já detalhados por Olson (1999), seja porque não é razoável imaginar a existência de um "altruísmo universal". Por outro lado, a solução Hobbesiana para a produção de um bem público (como a ordem social), que implicaria no monopólio do poder por um "outro", carrega problemas óbvios: qual o nível de confiança 
que se pode atribuir a este outro e qual a garantia de que este não vai desertar? Frente a estas possibilidades, mais uma vez o interesse individual elevaria a transgressão anterior à consecução do contrato coletivo ao patamar de melhor opção.

Putnam (2007) dialoga também com o chamado "novo institucionalismo", para o qual a existência de instituições formais seria capaz de reduzir os "custos de transação" inerentes à manutenção continuada de uma ação coletiva, tais como fiscalizar os atores individuais e garantir o cumprimento dos acordos necessários à provisão de um determinado bem coletivo. Para isto, a instituição deveria carregar elementos de otimização relativos à participação dos interessados na definição das regras de atuação, à definição coletiva de sanções para a deserção e ao baixo custo para resolução de conflitos. Mas restaria ainda uma questão, segundo Putnam: o que explicaria a formação destas instituições capazes de engendrar a superação dos dilemas da ação coletiva?

A resposta estaria um passo antes da própria formação das instituições e coloca em jogo o que Putnam denomina como "capital social", compreendido como um estoque de confiança mútua e disposição associativa que os membros de determinada comunidade (ou mesmo de uma sociedade mais ampla) carregam.

A superação dos dilemas da ação coletiva e do oportunismo contraproducente daí resultante depende do contexto social mais amplo em que determinado jogo é disputado. A cooperação voluntária é mais fácil numa comunidade que tenha herdado um bom estoque de capital social sob a forma de regras de reciprocidade e sistemas de participação cívica (PUTNAM, 2007, p. 177).

Ao contrário do capital monetário que em geral corresponde a um recurso privado, o capital social é um ativo público, na medida em que somente pode ser utilizado e consumido coletivamente. Por sua vez, a acumulação deste capital se faz pelo uso. Ou seja, se há 
confiança intersubjetiva entre os agentes, há maior probabilidade de cooperação (baseada na crença que o outro não vai desertar ${ }^{8}$ ). A cooperação eficaz gera mais confiança, o que engendra um círculo virtuoso de acumulação de capital social.

Assim, nestes ambientes em que há capital social abundante, há também cooperação e "sistemas de participação cívica" (PUTNAM, 2007, p. 183). Estes últimos imprimiriam variáveis fundamentais à cooperação. Isto porque incrementam os custos potenciais da deserção; geram regras robustas e continuadas de reciprocidade; difundem melhor as informações acerca da conduta e reputação de cada um (e, portanto, do grau de confiança que merece); e criam um modelo a ser racionalmente replicado por já ter provado sua potencialidade positiva. Com isto, a participação cívica se torna uma referência cultural que será progressivamente mais forte, na medida em que segue reduzindo os custos de transação inerentes à produção dos benefícios coletivos ${ }^{9}$. É hora de voltarmos aos nossos dados para que possamos analiticamente verificar como tais elementos referentes à cooperação e à associação para a produção de um bem coletivo se perfazem na experiência concreta de um Centro Comunitário de Produção voltado para a agricultura familiar.

8 Como lembra Putnam (2007), tal confiança imersa no capital social não é "cega", mas sim baseada no pressuposto de que neste ambiente cada um conhece a disposição do outro e, consequentemente, consegue mapear as alternativas de ação que este pode utilizar, bem como as consequências daí advindas. Neste sentido, cada um pode deduzir que ao outro será mais racional cooperar. Exatamente o contrário ocorre em ambientes com baixo índice de capital social.

9 Não podemos deixar de sinalizar que, apesar de Putnam (2007) ter construído um paradigma com ampla aceitação e forte propagação no campo das ciências sociais, a forma como este utiliza o conceito de capital social levanta considerações críticas desde que veio a luz. A parte mais substancial destas críticas se refere a certo determinismo de base "culturalista" que derivaria da aplicação do conceito. Nesta direção, o trabalho de Oakley e Clayton (2003), que analisa iniciativas de "empoderamento" de comunidades vulneráveis, pode ser tomado como um contraponto a perspectiva que estamos utilizando como base analítica neste artigo. Um valioso balanço crítico do conceito de capital social encontra-se em Abu-El-Haj (1999). 


\section{Associação comunitária e gestão do Centro Comunitário de Produção Boa Esperança, em Ponta Porã-MS}

Para que possamos compreender de forma mais precisa como se configuram os aspectos de confiança e o grau de participação política das famílias no projeto, devemos inicialmente demarcar as características daquelas que participavam do Centro Comunitário de Produção Boa Esperança quando realizamos esta pesquisa (entre final de 2013 e início de 2014).

Trata-se de um grupo muito pequeno, somente 16 famílias $^{10}$, com uma média de 4 moradores, nas quais a pessoa de referência no domicilio possuí entre 35 e 44 anos. Todos são agricultores familiares, que em momentos de escassez podem buscar a inserção em atividades rurais temporárias assalariadas, enquanto o conjugue mantém a produção dos insumos agropecuários. Destas 16 famílias, somente 3 não são beneficiárias do programa de transferência de renda Bolsa Família, voltado para populações pobres e miseráveis. Com a participação no Centro Comunitário de Produção a renda média mensal destas famílias aumentou, passando de $\mathrm{R} \$ 551,33$ para $\mathrm{R} \$ 806,00$. Não podemos afirmar que este aumento se deve exclusivamente a ganhos ligados à participação das famílias no projeto, pois outros fatores podem ter concorrido para esta configuração. No entanto, os dados qualitativos coletados no grupo focal realizado indicam que, ao menos na percepção dos agricultores familiares, o Centro Comunitário de Produção possibilitou melhora na aquisição de renda. Vale ressaltar que em geral as famílias possuem entre 12 e 13 animais, já que a dimensão do lote -6 hectares para cada assentado - não oferece condições de aumentar em larga escala esse número. Aqueles poucos

10 Nos demais sete CCPs instalados no assentamento também havia, naquele momento baixa adesão. A média de famílias vinculadas a estes era de 11,7, embora a capacidade média de incorporação ficasse em torno de 81,9. 
que possuem mais de 15 cabeças precisam utilizar áreas arrendadas de outros assentados.

Cabe agora apresentar a estrutura de representação da associação e da cooperativa que atuam junto ao Centro Comunitário de Produção Boa Esperança. A Associação dos Agricultores Familiares do Assentamento Itamarati II (AAFI) - criada em 2006, dois anos após a chegada das famílias - pretende representar o conjunto dos assentados. No entanto, de nenhum morador é solicitado que se associe formalmente ou que pague qualquer tipo de taxa ou mensalidade. Neste sentido, a AAFI possui uma estrutura de representação sui generis: a cada grupo de noventa famílias é "eleito" um conselheiro. No momento da realização da pesquisa haviam 23 conselheiros que efetivamente participavam das assembleias que tomam as decisões relativas à AAFI, e dos conselhos (fiscal e deliberativo), bem como da diretoria. Tal estratégia é apontada pela atual diretoria como necessária, tendo em vista a dificuldade de se encontrar um local adequado em que pudessem se reunir todas as famílias residentes. Ainda que somente algumas destas 90 famílias em questão exerçam seu direito de voto para escolha do conselheiro, o representante eleito aparece como convergência de todas. Os que votaram no conselheiro são considerados informalmente como sócios, ainda que, de fato, não sejam associados (no sentido de que nada assinaram, ou preencheram qualquer ficha de filiação).

Temos aqui um modelo verticalizado que é contraproducente a uma efetiva participação cívica. De resto, como lembra Putnam (2007), quanto mais horizontal forem as relações associativas, maior a probabilidade de êxito destas, uma vez que a horizontalidade facilita a confiança intersubjetiva. Ao contrário disto, a verticalização tende a gerar hierarquia e desconfiança. No caso aqui em tela, os agricultores familiares em geral acabam se distanciando das esferas de tomada de decisão que são fundamentais para a compreensão de toda a gestão 
do empreendimento do qual fazem parte. Além disso, muitas dessas famílias nem mesmo sabem que existe alguém que é responsável por sua representação na associação.

Para a gestão do Centro Comunitário de Produção foi criada a Cooperativa dos Agricultores Familiares do Assentamento Itamarati II (COOPERAAFI). É esta cooperativa que possui relação direta com os produtores do empreendimento, fazendo a captação de todo o leite produzido. A cooperativa iniciou suas atividades em 2010, meses antes de serem instalados os resfriadores que compõem os CCPs em operação no local. Segundo os dados coletados na pesquisa, a ideia de sua formação surgiu entre as lideranças do movimento e o objetivo seria alcançar melhorias para o assentamento, buscar formas de parceria para aumentar os recursos disponíveis para investimento e direcionar a produção do leite aos mercados que poderiam ser acessados. A COOPERAAFI considera informalmente como cooperado todo aquele produtor que entrega leite nos resfriadores, mesmo que este não tenha feito a adesão legal à cooperativa e que não seja associado à AAFI. O produtor entrega o leite e a cooperativa garante a compra da produção por um valor estipulado mensalmente.

A implantação da cooperativa buscou agregar os produtores - que até aquele momento entregavam o leite de forma individual e solapar a insegurança oriunda de tal formato de comercialização. Antes da cooperativa, portanto, os produtores eram submetidos ao baixo valor pago pelo litro de leite, à episódios de falta de pagamento do valor acordado e incerteza sobre a venda da produção - pois as empresas que faziam o recolhimento via de regra se ausentavam durante determinado período, fazendo com que a produção fosse perdida.

A cooperativa começou a recolher o leite dos produtores assentados em 2011. No mês de julho eram pagos $\mathrm{R} \$ 0,48$ pelo litro de leite pelas empresas privadas, que em outra época chegaram a pagar 
$\mathrm{R} \$ 0$,20. A partir de agosto de 2011, já com a atuação da cooperativa, o litro subiu para $R \$ 0,75$ (no momento da pesquisa pagava-se $R \$ 0,89$ ). A implantação da cooperativa, portanto, conseguiu aumentar o preço por litro e superou a questão do alinhamento - sempre para baixo promovido pelas empresas que faziam o recolhimento anteriormente, pois estas estabeleciam um cartel que deixava o produtor sem opções. Realizando a própria comercialização foi possível afastar os atravessadores que dificultavam o desenvolvimento da produção. Assim, a Cooperativa dos Agricultores Familiares do Assentamento Itamarati II, com os resfriadores mais próximos, aumentando o valor pago por litro e garantindo a compra de toda a produção, trouxe mais tranquilidade aos produtores familiares. No entanto, como já apontamos, somente 16 famílias se beneficiavam do CCP Boa Esperança no momento da pesquisa. Destas 16, somente uma era associada à AAFI (a do responsável pelo CCP) e duas eram cooperadas, sendo novamente uma delas a do responsável pelo CCP.

Apesar de pequena, toda a produção leiteira do empreendimento possui destino certo. Devemos lembrar que o resfriador instalado neste Centro Comunitário de Produção tem capacidade para absorver a produção diária de 170 famílias. Os dados qualitativos coletados em nossa pesquisa, indicam que cerca de 50 famílias haviam participado do esforço para a implantação da unidade e teriam mesmo começado a entregar leite no resfriador, mas este número foi progressivamente declinando devido a fatores variados. Entre estes fatores estariam a ausência de assistência técnica, a não adaptação de muitos à rotina da produção leiteira e o preço elevado da soja, que tem transformado pastos em plantações. Mas vale indagar se a baixa capacidade associativa não pode também ter contribuído com força para engendrar esta configuração encontrada em 2013-14.

A implantação do Centro Comunitário de Produção como um bem público foi estimulada pela Eletrobras, que forneceu os 
equipamentos e instalou a infraestrutura de fornecimento de energia elétrica. Mas os agricultores também tiveram que arcar com um custo individual relativo à mão-de-obra que pessoalmente disponibilizaram para a construção do prédio onde o resfriador foi disposto. A pesquisa não identificou a presença de free-riders neste processo. As 50 famílias que inicialmente aportavam leite no empreendimento haviam cooperado para a construção do mesmo e parte destas continuava se beneficiando do resfriador.

Para estes foi racional cooperar, visando um benefício futuro. Não havia uma sanção objetiva para a deserção, mas havia um estímulo concreto: reduzir as incertezas que tipicamente rondavam as relações individualizadas com as empresas compradoras e alcançar melhor preço de venda.

O problema é que este grupo, que se mobilizou para a produção de um bem coletivo e o gerou sem deserção (suplantando assim o "dilema da ação coletiva"), parou neste ponto. Mais especificamente, nossa hipótese é que não havia ali acumulação de capital social suficiente para o próximo passo, que seria a gestão coletiva do Centro Comunitário de Produção. Com isto a cooperativa se impôs como um novo comprador, mais confiável e perene, porque também mais próximo, mas ainda assim um comprador. É necessário aqui explicar melhor o problema. O modelo de gestão do Centro Comunitário de Produção via uma cooperativa (a COOPERAAFI) da qual 14 dos 16 agricultores familiares não são formalmente cooperados, enseja algumas questões que merecem atenção. Apesar de ser garantida a compra de toda a produção de cada família e o pagamento de um preço mínimo que se mantém acima do que era pago antes do funcionamento do Centro Comunitário de Produção, os produtores individualmente não possuem ideia do ciclo de produção e da gestão financeira que o envolve. Sua participação fica limitada à entrega do leite e ao recebimento do respectivo pagamento, não sabendo nem 
mesmo calcular o custo de produção até a chegada do leite ao resfriador e depois deste ser resfriado. Os produtores não têm ideia, portanto, da taxa de lucro do negócio, ou mesmo da taxa de administração cobrada pela cooperativa.

O baixo interesse em participar do processo global de produção é reconhecido e avaliado como um problema pelas próprias lideranças. Estas apontam que o interesse deveria ser muito maior, tendo em vista as necessidades e demandas do assentamento. Uma explicação para esta configuração relativa à participação é a falta de união dos assentados depois de passado algum tempo do recebimento de seus lotes. Ou seja, antes de serem assentados, quando lutavam juntos nos acampamentos do Movimento Sem Terra para receber sua propriedade e poder trabalhar, todos se mantinham mais unidos. Depois de assentados, teriam perdido a compreensão da ação coletiva e cada família passou a operar de forma isolada em sua propriedade, buscando formas próprias de sustento e tornando-se pouco permeáveis à participação política (segundo uma liderança entrevistada, esta dinâmica seria conhecida como "assentou, acomodou").

Assim, a relação estabelecida entre as famílias e o Centro Comunitário de Produção fica estritamente vinculada à entrega do produto e ao pagamento pela cooperativa, sem que exista nenhuma diferença entre o valor pago ao associado ou ao formalmente cooperado e aqueles que não são associados ou formalmente cooperados.

Nesta medida a cooperativa apresenta os mesmos problemas de participação da associação. Segundo levantamos nas entrevistas realizadas, mesmo no momento em que foi escolhida a família que ficaria responsável por "tomar conta" do resfriador do Centro Comunitário de Produção Boa Esperança, fundamental para o desenvolvimento do projeto, a participação foi escassa. Contrapondo estas informações com os dados obtidos no grupo focal realizado com representantes das famílias dos produtores, podemos perceber que 
este isolamento pode ser ainda mais profundo do que o já apontado. Em nenhum momento parece haver qualquer tipo de engajamento político ou mesmo vontade de organização, que tenha a coletividade como prioridade. Os assentados, apesar de saberem de forma difusa da existência de reuniões, quase nunca participam e a maioria não sabe nem que existe um conselheiro que é seu representante nas assembleias que definem a trajetória do assentamento. Embora não apresentem justificativas para a não participação. $\mathrm{O}$ trecho abaixo, extraído de um grupo focal realizado com os agricultores familiares, é bastante elucidativo:

- Eu lembro que uma vez que teve uma reunião pra tirar um representante pra fazer parte na associação. Aí o pessoal não quis, ninguém quis participar e nem quis tirar um representante. Aí ficou sem. Aí de lá pra cá não teve mais reunião. Daí o Paulo ${ }^{11}$ fez uma reunião, ele mais o Pedro mais o José pra fazer esse representante e daí não houve também. Nesse dia já virou discussão e acabou lá e saiu de lá da reunião e não tirou esse representante. Aí de lá pra cá eu não fiquei sabendo. Aí agora há poucos dias eu fiquei sabendo que o Roberto estava de representante. Eu falei, mas por mim ele não foi votado, se ele está participando é por conta dele entendeu e o pessoal da comunidade também não sabe não, da minha comunidade não sabe que ele faz parte. (Grupo focal com beneficiários do CCP Boa Esperança)

Os aspectos ligados à questão de gênero também representam um ponto fundamental que aprofunda o problema da participação dos assentados. Segundo os dados qualitativos coletados, todos os entrevistados admitem que a participação das mulheres nas esferas existentes de decisão é praticamente nula, ainda que entendam que esta deveria ser maior. As entrevistas apontam que a atuação das mulheres está mais voltada para a produção do leite em si - na ordenha e por vezes no transporte - e nas questões da casa, reproduzindo um modelo de desigualdade de gênero.

11 Todos os nomes citados nas transcrições foram alterados. 
Schmitz e Santos (2013), em estudo que transversa a perspectiva de gênero no trabalho da produção leiteira, aponta que no que tange a recursos financeiros, os elementos simbólicos que atribuem ao homem a tarefa de fazer o seu gerenciamento são reproduzidos na esfera rural, mesmo quando há modernização da produção. São os homens os responsáveis pelas finanças enquanto que às mulheres cabe o trabalho cotidiano, não remunerado e repetitivo. Em nosso estudo, as mulheres do assentamento não possuem uma inserção mínima nas esferas de decisão política, mas, por outro lado, participam efetivamente da produção do leite e em alguns casos na entrega do produto, sendo fundamentais para o sucesso do empreendimento. Oestudo de Schmitz e Santos (2013) corrobora os achados de nossa pesquisa. Segundo os autores, à mulher cabe principalmente o trabalho de ordenhar as vacas e limpar os equipamentos. Alguns serviços são compartilhados entre os sexos, no entanto, nas participações externas em que alguém precisa se afastar da produção para se reunir em assembleias, capacitações técnicas em geral, etc., são os homens que comparecem.

Também segundo Magalhães (2009), a naturalização das atribuições femininas e masculinas que privilegiam o modo patriarcal de conduta social são reproduzidas na atividade leiteira. Em seu estudo que aborda a "masculinização" da produção de leite, Magalhães identifica que eles e elas não conseguem justificar o porquê de determinada divisão do trabalho. Assim, a participação das mulheres fica restrita ao universo doméstico de produção, reproduzindo em amplo aspecto a percepção de que a atividade feminina deve ser voltada para tais tarefas, longe de uma participação mais efetiva na política. Em nenhum momento da coleta de dados foi identificada alguma possível estratégia das lideranças locais para que essa participação feminina se tornasse mais efetiva ou mesmo fosse incentivada.

Voltando à questão da cooperativa, na pesquisa realizada foi possível identificar que os 16 agricultores familiares demonstram 
concordar com a forma de gestão na qual a COOPERAAFI dirige todo o processo de recolhimento e venda do leite, bem como cobre os custos de operação do resfriador, sem que haja qualquer transparência financeira ou divisão de lucros.

Mas eu estou perguntando da forma da gestão, de como trabalha o CCP. Aqui é a cooperativa que faz a gestão. Outra forma seria vocês produtores fazerem a gestão...

- Mas não ia dar não.

- Eu acho que não.

Por que não?

- Porque que nem eu falei no começo tem gente que pensa de um jeito. - - Tem um que pensa de um tipo, tem outro que pensa de outro...

- Daí vai dar briga.

- Aí já complica. Eu no meu modo de pensar eu acho que do jeito que está pela associação está bom. É que nem eu falei uma parte concorda e uma parte já não concorda e dá briga.

- [...] E outra coisa, o leite a gente recebe o nosso valor no dia certo, e não desconta nada e não tem pagamento de luz e nem nada; a cooperativa é responsável desses gastos. Então eu acho que não tem nada de errado eu acho que está normal. (Grupo focal com beneficiários do CCP Boa Esperança)

Nesta direção, seja por parte da associação ou da cooperativa, não existe nenhum planejamento para buscar aumentar o número de associados/cooperados. Nenhuma estratégia é traçada para que estas instâncias sejam reconhecidas e fortalecidas, fundamentais que são na organização da empreitada em questão. Como vimos, a relação fica estreitamente vinculada à entrega do leite que se transforma, na realidade, no único elo que une os agricultores familiares beneficiários do Centro Comunitário de Produção e a associação e a cooperativa. Mais uma vez, elementos coletados no grupo focal nos auxiliam a compreender as percepções em jogo:

O que vocês acham desta forma como funciona a associação?

- Eu não sei de nada não. O negócio da associação lá eu não sei quem é presidente, nem quem é tesoureiro, quem é secretário, 
nem nada.

- Nem eu.

- Se eu falar pra você que eu sei, eu estou mentindo. Então já falo logo a verdade, eu não sei quem é. Se falar pra mim lá, o presidente é o fulano, eu vou falar que eu não sei por que eu nunca participei de nenhuma reunião.

E os outros?

- A mesma coisa.

- Não sei também. (Grupo focal com beneficiários do CCP Boa Esperança)

É necessário enfatizar que a criação das duas entidades (a AAFI e a COOPERAAFI), em ambiente de baixa presença de capital social, ainda que importante para todo o processo de implantação do Centro Comunitário de Produção enquanto um bem coletivo, não gerou a possibilidade de reversão da configuração inicial. Ou seja, não ocorreu a partir destas instituições nenhuma forma de desenvolvimento de capital social ou mesmo de acréscimo de margens de confiança que pudessem ampliar a percepção da necessidade de engajamento coletivo ou organização produtiva. Por sua vez, o funcionamento do empreendimento também não gerou capacidade associativa ou incrementou a organização na base dos agricultores, pelo contrário, ensejou um formato de gestão verticalizado.

É possível levantar a hipótese de que a cooperativa foi criada exatamente para preencher este déficit de participação e organização. Uma vez criada, sob formato vertical, não conseguiu mobilizar os assentados, mas também não recebeu qualquer resistência destes. Por conta disto, foi progressivamente maximizando sua atuação até chegar ao ponto atual, no qual as poucas famílias do assentamento que ainda participam do empreendimento não possuem qualquer forma de controle sobre o Centro Comunitário de Produção. Somente entregam o leite e recebem um pagamento por este, sem ter qualquer informação acerca do custo de operação do equipamento, do preço pelo qual o leite é vendido e do lucro obtido pela cooperativa. Assim, 
a ausência de capital social condicionou uma situação na qual após o primeiro ciclo de cooperação, que gerou o CCP como um bem coletivo, não se seguiram de forma virtuosa novas iniciativas associativas. Como observamos nos dados coletados durante a pesquisa, após a implantação do empreendimento se seguiu um vácuo organizacional que foi preenchido de maneira verticalizada pela associação de moradores, de início, e pela cooperativa, em seguida.

Os agricultores familiares foram capazes de se associar e individualmente prover a quantidade de trabalho necessário para a construção do prédio. Mas não se interessaram por investimentos posteriores, que implicavam em custos de transação mais elevados, que deveriam ser materializados em reuniões, discussões para definição de regras, atuação junto à burocracia pública para obtenção de certificados sanitários, registros cartoriais, gestão financeira, etc. Preferiram ser somente entregadores de leite, se satisfazendo com o benefício alcançado relativo ao melhor preço e à maior segurança de mercado. Outros agentes ocuparam este espaço, implementaram a gestão verticalizada do bem coletivo e não são perguntados nem mesmo sobre suas margens de lucro.

\section{CONSIDERAÇões FINAIS}

Os estudos acerca da lógica da ação coletiva objetivam a compreensão dos elementos que podem explicar por que indivíduos se unem para desenvolver uma atividade em comum ou por que se recusam a fazê-lo. Segundo Olson (1999), embora a ação coletiva se refira a algo compartilhado por um grupo, isto não significa que a participação de cada um não seja motivada pelo interesse individual, o que torna racional, dependendo do contexto, tanto a cooperação quanto a deserção. Olson (1999) utiliza, como vimos, a noção de "benefício coletivo" como ponto central para a compreensão dos 
dilemas da ação coletiva. Tratar-se-ia de um benefício que, uma vez utilizado por um grupo, não pode ser negado a qualquer membro participante deste, ainda que esse membro não tenha feito qualquer esforço para a produção do mesmo. $\mathrm{O}$ indivíduo, sabendo que o benefício coletivo não poderá lhe ser negado, tende a não despender os custos necessários à sua consecução. Com isto são sobrecarregados aqueles que buscam a obtenção do bem e investem recursos nisto. Esse é o chamado dilema do free-rider.

A configuração que encontramos no Centro Comunitário de Produção Boa Esperança, que foi alvo da pesquisa que originou este artigo, parece ser o exemplo de uma deserção generalizada (como todos querem "pegar carona", o bem coletivo não é gerado), mas que se deu após uma rodada de cooperação perfeita. Na concepção de Olson (1999), esta deserção geral não seria tipicamente encontrada em grupos pequenos, como os que estamos estudando. Isto porque nestes, como o benefício será dividido entre poucos, os ganhos serão mais significativos e visíveis para cada um individualmente e, portanto, a tendência é que haja maior estímulo à cooperação. Além disto, o custo de transação do controle da deserção é menor num ambiente em que todos se conhecem. Segundo os dados coletados, para a produção do prédio que abriga o Centro Comunitário de Produção, a participação em mutirão de aproximadamente 50 famílias que inicialmente começaram a entregar leite naquele espaço foi realizada sem a presença ostensiva de free-riders. No entanto, uma vez iniciada a operação do $\mathrm{CCP}$, não houve adesão da base dos agricultores familiares à gestão do mesmo. Todos desertaram. Com isso, a associação comunitária criou uma cooperativa quase sem cooperados e verticalizou a gestão do resfriador. Mas o que explica a situação de deserção perfeita que encontramos?

Todos os elementos apontam para a existência de índices muito baixos de capital social naquele espaço, a despeito de ali estarem 
reunidas famílias que passaram anos lutando pela reforma agrária em acampamentos do Movimento dos Trabalhadores Sem Terra. Os dados qualitativos coletados indicam que, antes da distribuição dos lotes para cada produtor, existia uma maior interação entre eles, uma vez que lutavam por objetivos comuns em acampamentos e mesmo invasões. Após cada família começar a sua própria produção, esses laços acabaram se enfraquecendo, uma vez que as necessidades de cada grupo doméstico suplantaram as coletivas. E essa conotação se insere na questão da ausência de vínculos com a associação comunitária que se coloca como a representante do assentamento. Com um sistema sui generis de representatividade, no qual um "representante" é escolhido para cada 90 famílias através de um processo de eleição do qual nem todos tomam conhecimento, a inserção da associação no tecido social é muito baixa. Os produtores com os quais nos relacionamos nesta pesquisa estavam absolutamente distantes dos processos associativos e, consequentemente, dos espaços de decisão política, mesmo quando estes implicavam diretamente em aspectos relacionados ao cotidiano do Centro Comunitário de Produção - seja no campo da gestão operacional ou financeira do mesmo.

Se não existia por parte dos assentados interesse nessa participação, por sua vez, a associação não programava nenhum esforço no sentido de tentar reverter esse quadro, resumindo sua atuação, junto com a cooperativa, à captação do leite produzido e sua venda para grandes empresas. $\mathrm{O}$ número ínfimo de cooperados e associados confirma esta situação. Qualquer produtor que entregue leite na cooperativa é considerado cooperado, mesmo que não seja de fato. As indagações feitas aos produtores sobre sua participação ou mesmo conhecimento destas organizações conseguem, no máximo, respostas como "já ouvi falar", "não conheço, mas sei que tem" ou "eu não sei, só vou lá e entrego o leite". Esta última resposta, por sinal, é sintomática. Ela acaba por resumir a verdadeira relação que 
se estabeleceu entre a cooperativa e os produtores: compradores e vendedores. Esta situação acaba criando um modelo justamente oposto ao princípio de cooperação, uma vez que restringe as possibilidades de interação e hierarquiza os participantes - elementos que tendem a realimentar um ciclo de baixa confiança, verticalização e esvaziamento da ação coletiva. Nesse sentido, questões como confiança, participação e coletividade perdem espaço simplesmente para a garantia de venda da produção por um preço melhor do que era praticado no assentamento antes do funcionamento do Centro Comunitário de Produção.

Toda a credibilidade da cooperativa está calcada nesse aspecto. Antes havia insegurança e preços baixos e hoje tais problemas foram sanados. Ainda que isto não seja pouco - já que antes do Centro Comunitário de Produção, além do preço baixo, não existia nem a garantia da coleta permanente do leite produzido -, não é o suficiente para que o projeto se expanda ou para que a comunidade possa alcançar ganhos mais amplos de bem-estar. Além disto, se de fato o CCP auxiliou o incremento da renda de quase todas as 16 famílias pesquisadas, este dado positivo atingiu poucas unidades domésticas no conjunto do assentamento, pois a adesão ao projeto se mostrou baixa.

A ação da cooperativa corresponde a uma gestão econômica que é apoiada pelos produtores familiares, mas que está longe de incrementar a organização política autônoma e a capacidade associativa. Em âmbito mais geral, o aprendizado associativo que poderia ter sido gerado através da gestão do empreendimento também não foi aproveitado. Assim, a atuação política da comunidade para resolução de problemas relativos ao bem-estar local, como acesso à saúde e qualidade da educação oferecida no assentamento, é quase nula. Por sua vez, também não houve alteração na capacidade da 
comunidade de se organizar visando obter engajamento em novos projetos de geração de renda.

\section{REFERÊNCIAS}

ABU-EL-HAJ, Jawdat. O debate em tomo do capital social: uma revisão crítica. Boletim Informativo Bibliográfico, Rio de Janeiro, n. 47, 1999.

CARMO, René Becker Almeida. A questão agrária e o perfil da agricultura brasileira 1999. Bahia Agrícola, Eunápolis, v. 4, n. 1, 2000.

GUANZIROLI, Carlos Enrique; CARDIM, Silvia Elizabeth C. S. (Coord.). Novo retrato da agricultura familiar: o Brasil redescoberto. Brasília: Projeto de cooperação técnica FAO/INCRA, 2000.

MAGALHÃES, Reginaldo Sales. A masculinização da produção de leite. Revista Economia e Sociologia Rural, Brasília, v. 47, n. 1, 2009.

OAKLEY, Peter; CLAYTON, Andrew. Monitoramento e avaliação do empoderamento ("empowerment"). São Paulo: Instituto Polis, 2003.

OLSON, M. A lógica da ação coletiva. São Paulo: EDUSP, 1999.

PUTNAM. Robert. Comunidade e democracia. Rio de Janeiro: FGV, 2007.

SAMUELSON, Paul A. The pure theory of public expenditure. Review of Economics and Statistics, Cambridge, v. 36, n. 4, p. 387-389, Nov. 1954.

SANTOS, C Christiane Fernandes et al. A agroecologia como perspectiva de sustentabilidade na agricultura familiar. Revista Ambiente e Sociedade, São Paulo, v. 17, n. $2,2014$.

SCHMITZ, Aline Motter; SANTOS, Roselí Alves. A produção de leite na agricultura familiar do Sudoeste do Paraná e a participação das mulheres no processo produtivo. Revista Terr@Plural, Ponta Grossa, v. 7, n. 2, 2013.

WANDERLEY, Maria de Nazareth Baudel. Agricultura familiar e campesinato: rupturas e continuidade. Estudos Sociedade e Agricultura, Rio de Janeiro, v. 21, 2004. 